\title{
Reform and innovation of graduate management mode in agricultural University Yang $\mathrm{Da}^{1, \mathrm{a}}$ \\ ${ }^{1}$ Jilin Agricultural University, Jilin 130000, China \\ ayangnan1983116@163.com
}

Keywords: Agricultural universities, computer, graduate student, management mode.

\begin{abstract}
In order to improve the management level on graduate student in agricultural colleges and universities, train talented person in the field of agricultural informationization and promote the development of agricultural informationization innovation in China. This paper is combined with the characteristics of graduate student in agricultural colleges and universities to analyze problems what are existing in the graduate student's management work of computer application in the agricultural colleges and universities. From the reality on the grassroots work of graduate student's management to research the graduate student's management mode of computer application major in agricultural colleges and universities. The management mode can emphasize the importance of graduate student's management work in colleges and universities and highlight the characteristics of graduate student's education in computer application field. Let the graduate students of computer application have their own advantages in the increasingly competitive environment.
\end{abstract}

\section{Introduction}

With the rapid development of IT industry, the enrollment scale on graduate student of computer application major has also been gradually expanding in agricultural colleges and universities. And the admission direction of graduate student is become wide in agricultural colleges and universities. The major and level become largely different because the students are from all over the country and the students have different age and experience. Under the market economy and the environmental impact of economic globalization, the graduate student's thought condition, value orientation, moral concept and so on have become more and more complex. Because of the existence of these complex situations, the graduate student's management and education work will become more difficult in agricultural colleges and universities. The graduate student's management work will face new opportunities and challenges in agricultural colleges. The colleges and universities can better adapt to a lot of demands for high-level agriculture person in China according to improve and innovate the graduate student's management mode. The graduate student's management workers need to have good management ability to cultivate higher professional agriculture talents in agricultural colleges and universities. The graduate student's management work in colleges and universities is a very important task what train and develop high skills in the process of high-quality talent. Graduate student's management work runs through in the whole process of education in colleges and universities. It runs through the teaching, scientific research and subject construction three links.

\section{The present situations and existing problems of graduate student's management mode in agricultural colleges and universities.}

The colleges and universities don't pay attention enough to the graduate student's management. General agricultural colleges think that the graduate student's ability is more stronger than undergraduate student on psychology and knowledge from undergraduate level to graduate level. Some graduate students in colleges and universities even participated in work, such graduate student's life experience is very rich. At the same time they have self management ability and self handling ability. Agricultural colleges ignore the characteristics of graduate student groups. 
Agricultural colleges just copy a set of patterns of undergraduate student to the graduate student's management mode. The student management work of agricultural colleges and universities only stay in the simple level of information announcement, enrollment file and safety management. The departments are lack of attentions on graduate student's management degree and professional management talent. The cattle type of graduate student's management work is existing due to various factors.

The daily routine management of graduate student in agricultural colleges is not in place. Some graduate students are already married, they not only shoulder the social responsibilities but also shoulder the heavy family responsibilities. They use reality view to think and solve problem. Part of the graduate students' ages are larger, they generally do not overly rely on the family to graduate school. The graduate student's management is not suit for students. Take safety education, rewards and punishments system, dormitory management, employment guidance to do a centralized management of daily affairs. Graduate student managers think that graduate students already have abilities of solution and management. There is no personal daily affairs management as work focus. Mentor's energy can not be balanced. They can't take too much time to guide and care about their students after teaching and researching work. Teachers can't concentrate on graduate student's research guidance better than academic affairs.

\section{Agricultural colleges and universities should strengthen and improve the methods of graduate student's management mode along with the economic globalization}

Science and technology gradually become the first productive force. To do a good job on graduate student's management of computer application in agricultural colleges is the inevitable requirement of society and knowledge economy. Workers in agricultural colleges and universities should work by different levels and take stress to insist on combining education with management. These steps should be according to the characteristics of the graduate student work. The quality and ability of graduate student can represent a comprehensive ability level of colleges and universities. The graduate student's management work should be in the clear direction and improve the comprehensive level of graduate student's management step by step in agricultural colleges.

To attach importance on graduate student's management work because the agricultural colleges plays a more important position in the development of the comprehensive strength. Graduate student's management work is an important part of graduate education, colleges should give great attitude to the importance of graduate student's management. All leaders of agricultural colleges and universities should attach great importance to the management of graduate students. In this way, graduate management department can attach great importance to graduate student's management work. They also can cooperate and implement the graduate student's management work very well. The graduate student's management can't separate, graduate management department should focus all of the work by concentrating the power of graduate student's management work. Graduate student's management work should be based on the academy, decentralized management system. The graduate management should adjust measures for local conditions. This kind of work method can make graduate student's management become a full-time management. Various departments and the mentors should further improve the level of full-time graduate student's management work.

The graduate management department should strengthen daily work of graduate management in agricultural colleges. The management staffs in agricultural colleges should strengthen management efforts on the graduate student's daily life. This is the important guarantee of graduate student's management. Graduate student counselor is frequently contact with graduate students. So graduate student counselor must strengthen the exchange among graduate students and understand their life and thought at any time. Graduate student counselor should care about the daily life of graduate student. So they can establish friendly relations with students. Counselor's work can provide a good and important guarantee for graduate student's management. Agricultural college's departments should fully exert their services and management functions and create a more convenient and favorable conditions for study and life of the graduate student groups. 


\section{Conclusion}

From above what has been discussed, graduate student's management work in agricultural colleges and universities should find out the graduate management mode according to the characteristics and situations of the graduate student groups. The new form, new method and new idea make them become high qualified person who possess enormous perspectives, knowledge, comprehensive ability and moral. The management of graduate student's fundamental starting point is to improve the personnel training quality in general colleges and universities. No matter what kind of graduate students in colleges and universities take management mode and operation mechanism is to achieve this goal. We believe that colleges and universities and innovation management modes can also go further with the development of an innovative country strategy. Management of graduate students in colleges and universities can provide important support for the management and training high quality talents.

\section{Acknowledgments}

At the point of finishing this paper, I'd like to express my sincere thanks to all those who have lent me hands in the course of my writing this paper. First of all, I'd like to take this opportunity to show my sincere gratitude to my supervisor who has given me so much useful advices on my writing, and has tried his best to improve my paper. Secondly, I'd like to express my gratitude to my colleague who offered me references and information on time. Last but not the least, I'd like to thank those leaders, teachers and working staff . Without their help, it would be much harder for me to finish my study and this paper.

\section{References}

[1] John H. Schuh and Associaties, Assessment Methods for Student Affairs, San Francisco, 2009.

[2] Kezar A, Achieving student success: Strategies for creating partnerships between academic and student affairs, Journal, 2003a.41. 